\title{
Numerical simulation of the fluid dynamics within the tissue engineering scaffolds micro-tubes
}

\author{
Jingzhi Jiang ${ }^{1}$, Yuyao Jia ${ }^{1}$, Haiting Cui ${ }^{1}$, Peiying Peng ${ }^{1}$ and Qinggang Liu ${ }^{1}$ \\ ${ }^{1}$ Mechanical engineering Department, Hebei University of Science and Technology,Hebei, China
}

\begin{abstract}
The core of tissue engineering is the fabrication of a complex three-dimensional space with cells and biomaterials. In the development of porous scaffolds in vitro, no matter the seed cells ran into the scaffold, or its excretion of waste discharged scaffolds, they both need the nutrient solution to be brought into or taken out. Therefore, the flow of the nutrient solution, cells and metabolic waste for the profitable living in vitro culture plays a significant role. the paper constructed bone scaffold models of different geometric parameters, analog cells, and nutrient solution flow conditions in the scaffolds using the FLUENT software. By making a contrastive analysis with the simulated result, the internal organizational design parameters of scaffold for tissue engineering is optimized and a certain amount of data and a theoretical basis for the internal bone scaffold structure design is provided.
\end{abstract}

Keywords: Tissue engineering; Scaffold models; Operating parameters; Velocity distribution

\section{Introduction}

From the source map of blood supply for bone, the outer of the Haversian canal has multi-layer bony plates those are centered around the center, arranging in concentric circles, which constitute bone unit with Haversian canal, known as the Harvard system. Harvard system connects with the Volkmann canals compose mainly channel for transport nutrients, which provides a good space and access for the seed cell proliferation, scaffolds in growth as well as the exchange of nutrients and metabolites discharge.

Based on the design and development of artificial bone, in view of the ratio of the actual bony structure, the model of bony scaffold was established and the fluid dynamics of cell and nutrient solution within the scaffolds are stimulated.

\section{Model establishing}

Nutrient solution and bone cells are transported to bone scaffolds by Volkmann canals. The fluid flow in the bone scaffold is a mixture of nutrient solution and bone cells. The density of nutrient solution used is $1100 \mathrm{~kg} / \mathrm{m}^{3}$, viscosity is $0.0018 \mathrm{~Pa}$.s. The density of bone cell used is $1200 \mathrm{~kg} / \mathrm{m}^{3}$ and volume fraction is 0.02 which ratio of the mixture is small. The average velocity of the nutrient solution flow is $0.19 \mathrm{~m} / \mathrm{s}$. Based on above, the density of the mixture of nutrient solution and bone cell is determined as $1100 \mathrm{~kg} / \mathrm{m}^{3}$, the viscosity is $0.0018 \mathrm{~Pa} \cdot \mathrm{s}$, and the initial flow rate is set to $0.19 \mathrm{~m} / \mathrm{s}^{[1-3]}$. Because of the flow rate of the nutrient solution and the cell is small, and its viscosity is large, according to the Reynolds number formula, the Reynolds number is calculated as 244 , which is much less than 2000 . That means the flow is an incompressible laminar flow. The laminar flow model calculation is adopted ${ }^{[4]}$.

\section{Simulation results and analysis}

\subsection{The effect of Haversian canal length}

Fig. 1 is the flow velocity and pressure distribution of the mixture of the nutrient solution and cells in the scaffold microtube. The intersection angle of Harvard's and Volkmann canal is $45^{\circ}$. The diameter of Harvard's canal is $0.6 \mathrm{~mm}$ and the lengths are respectively $1.5 \mathrm{~mm}, 2 \mathrm{~mm}$ and $3 \mathrm{~mm}$. The figures of velocity distribution show that the flow rate decreases obviously when the mixture solution flow from the first layer of Haversian canal to the Volkmann canals. In the second layer of Haversian canal, the flow rate of the mixture solution in the central three Haversian canals increased, but lower than the rate first layer of Haversian canal. With the increasing of the Haversian canal length, the fluid flow rates of each tube will be decreased. 
When the fluid flows to the Volkmann canals, the flow is influenced by the local resistance generated the bifurcation canal, which makes the rate of the Volkmann canals reduce. In the central three Haversian canals, fluids from two Volkmann canals converge there, flow increases and results in the flow rate among increases.
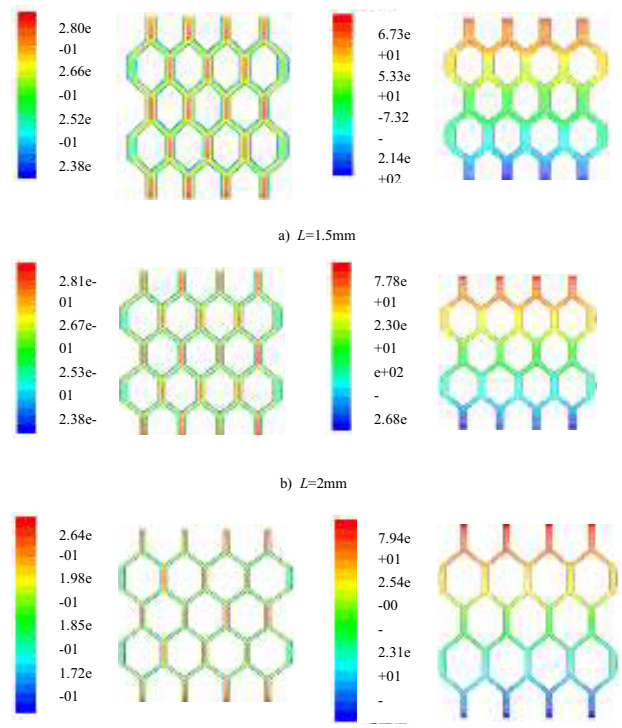

c) $L=3 \mathrm{~mm}$

Fig. 1. Velocity and pressure distribution in different lengths of Harvard canal

\subsection{The effect of Haversian canal diameter}

Fig 2 is the flow velocity and pressure distribution of the mixture of the nutrient solution and cells within the scaffold. The intersection angle of Harvard's and Volkmann canal is $45^{\circ}$. The length of the Haversian tube is $1.5 \mathrm{~mm}$, and the diameter is respectively $0.4 \mathrm{~mm}, 0.6 \mathrm{~mm}$ and $0.8 \mathrm{~mm}$. Comparing to the velocity

distribution of Figure 1 a)and Figure $2 \mathrm{a}$ ), b), when Harvard's canals diameter is $0.4 \mathrm{~mm}$ and $0.6 \mathrm{~mm}$, the velocity of the Volkmann canal and Haversian canal are greatly different which shows an adverse impact on the deposition of cell in
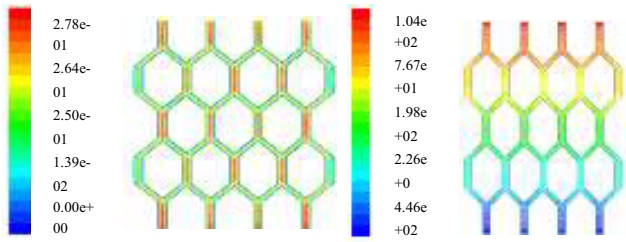

a) $d=0.4 \mathrm{~mm}$
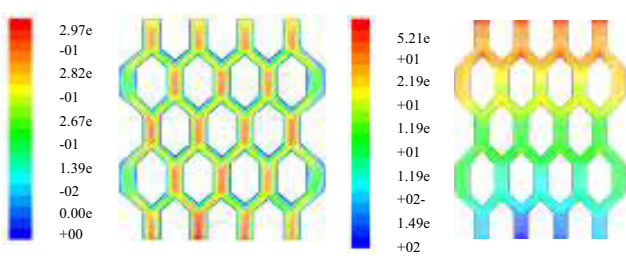

b) $d=0.8 \mathrm{~mm}$

Fig. 2. Velocity and pressure distribution in different diameter of Harvard canal

micro-tubes. In the bone scaffold of Haversian canal with the diameter of $0.8 \mathrm{~mm}$, fluid flows 
within each micro-tubes are uniform and the average flow rate reaches around $0.2 \mathrm{~m} / \mathrm{s}$, which is beneficial to the transport of cells and nutrient solution.

When Haversian canal diameter decrease, the entrance resistance increase, the loss of local energy increases, the velocity of the fluid in the Volkmann canal is reduced quickly. Therefore, the fluid of the first layer in the Volkmann canal has a larger flow rate, when the fluid in the Volkmann canals confluence into Haversian canal, due to Haversian canal's diameter is bigger than the Volkmann canal, the flow rate will increase after the fluids confluence, but the increase is not obvious. The situation in other layers is similar to the first layer. Within the range of this simulation, Haversian canal diameter is larger, the fluid flow rate of in each micro-tube bone scaffold is relatively uniform, and the average flow will reach to about $0.2 \mathrm{~m} / \mathrm{s}$.

\subsection{The effect of the angle between Haversian and the Volkmann canal}

Fig2 b)and Fig3 a), b) (the left is velocity distribution) are the flow velocity and pressure distribution of the
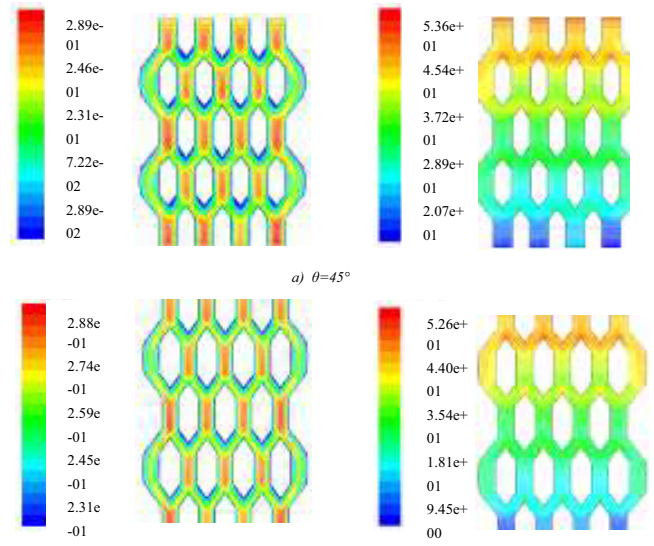

b) $\theta=37.5^{\circ}$

Fig. 3. Velocity and pressure distribution in different angle between Harvard's tube and Volkmann tube mixture of nutrient solution and cells in the scaffold. The length of the Haversian canal is $1.5 \mathrm{~mm}$, the diameter is $0.8 \mathrm{~mm}$ and the angle between Harvard's and the Volkmann canal are respectively $30^{\circ}, 37.5^{\circ}$ and $45^{\circ}[5-6]$. When the angle is $30^{\circ}$, the upper of the Volkmann canal fluid flow rate is greater, which is $2.17 \mathrm{e}-01 \mathrm{~m} / \mathrm{s}$, but the flow rate in the tube is not uniform.

With the angles become bigger, the flow rate of fluid in the Volkmann canals is gradually reduced and the fluid flow within the tubes is uniform. When the angles are $37.5^{\circ}$ and $45^{\circ}$, the flow rate of the upper of the Volkmann canal are $1.93 \mathrm{e}-01 \mathrm{~m} / \mathrm{s}$ and $1.88 \mathrm{e}-01 \mathrm{~m} / \mathrm{s}$ respectively; meanwhile, with the angle increase, the fluid rate of each micro-tube in bone scaffold are more uniform.

When the angle is large, most of the fluid in the Haversian canal is shunt by the Volkmann canal. When the fluid flows into the bottom of Harvard canal, the volume and velocity of fluid decrease. Whether the fluid flow from the Haversian canal into the Volkmann canals or on the contrary, the flow of fluid are uniform, but the uniform flow area is smaller than the area of $45^{\circ}[7]$.

\section{Conclusion}

With the Haversian canal length decreasing, the fluid flow rate of each of the microtube are slightly reduced, the flow rate in each the mirotube is uniform, which is conducive to the delivery of nutrient solution and cells. With Haversian canal diameter increasing, the fluid flow rate of in the each pipeline bone scaffold is relatively uniform, and the average flow will reach to about $0.2 \mathrm{~m} / \mathrm{s}$. With The angle between the Harvard's tube and the Volkmann canal increasing, it is easier to transport the cells and the nutrient solution and more suitable for tissue engineering scaffolds. Within the range of this simulation, the optimized structure parameter of bone scaffold is the length of Haversian canal of $0.15 \mathrm{~mm}$, Haversian canal diameter of $0.6 \mathrm{~mm}$, the angle between the Harvard's tube and the Volkmann canal of $45^{\circ}$. 


\section{References}

1. C. PHILIPPE, D. STEPHANE, PAURELIEN, et al. Chapter 28-Blood Rheology, Blood Flow and Human Health. Nutrition and Enhanced Sports Performance, 2013: 283-293

2. Qin T J. Hemorheological Beijing: People's Medical Publishing House, 1999

3. Philippe Connes, Stephane Dufour, Aurelien Pichon, et al. Nutrition and Enhanced Sports Performance. Amstardam:Elsevier, 2013:283-293

4. Liu H L,Hoff B H,Anthonsen T. Chemo-enzymatic synthesis of the antidepressant duloxetine and its enantiomer . Chirality., 2000, 12 (1):26-29

5. Emerson dos Reis, Leonardo Goldstein Jr. Fluid dynamics of horizontal air-water slug flows through a dividing Tjunction. International Journal of Multiphase, 2013,50:58-70

6. Tao Z L. Biological Fluid Mechanics [M] Beijing: Science Press, 1984

7. Huang W X, Chen W M Engineering Fluid Mechanics Beijing: Chemical Industry Press, 2001 